Chapter 4

\title{
Microstructure and Mechanical Properties of High Strength Two-Phase Titanium Alloys
}

\author{
J. Sieniawski, W. Ziaja, K. Kubiak and M. Motyka \\ Additional information is available at the end of the chapter \\ http://dx.doi.org/10.5772/56197
}

\section{Introduction}

Two-phase titanium alloys constitute very important group of structural materials used in aerospace applications [1-3]. Microstructure of these alloys can be varied significantly in the processes of plastic working and heat treatment allowing for fitting their mechanical properties including fatigue behaviour to the specific requirements [4-6].

The main types of microstructure are (1) lamellar - formed after slow cooling when deformation or heat treatment takes place at a temperature in the single-phase $\beta$-field above the socalled beta-transus temperature $\mathrm{T}_{\beta}$ (at which the $\alpha+\beta \rightarrow \beta$ transformation takes place), consisting of colonies of hexagonal close packed (hcp) $\alpha$-phase lamellae within large body centered cubic (bcc) $\beta$-phase grains of several hundred microns in diameter, and (2) equiaxed - formed after deformation in the two-phase $\alpha+\beta$ field (i.e., below $\mathrm{T}_{\beta}$ ), consisting of globular $\alpha$-phase dispersed in $\beta$-phase matrix [7-8].

The first type of microstructure is characterized by relatively low tensile ductility, moderate fatigue properties, and good creep and crack growth resistance.

The second microstructure has a better balance of strength and ductility at room temperature and fatigue properties which depend noticeably on the crystallographic texture of the hcp $\alpha$-phase.

An advantageous balance of properties can be obtained by development of bimodal microstructure consisting of primary $\alpha$-grains and fine lamellar $\alpha$ colonies within relatively small $\beta$-grains (10-20 $\mu \mathrm{m}$ in diameter) [9-10].

In the following sections the relations between microstructure morphology and mechanical properties of selected high strength two-phase titanium alloys were analysed. 
Dilatometric tests, microstructure observation and X-ray structural analysis were carried out for cooling rates in the range of $48-0.004^{\circ} \mathrm{C} \mathrm{s}^{-1}$ and time-temperature-transformation diagrams were developed for continuous cooling conditions (CCT).

The influence of the quantitative parameters of lamellar microstructure on the tensile properties and fatigue behaviour of selected two-phase titanium alloys was analysed. Rotational bending tests were carried out to determine high cycle fatigue (HCF) strength at $10^{7}$ cycles.

\section{High strength two-phase titanium alloys}

The materials tested were high strength, two-phase $\alpha+\beta$ titanium alloys: Ti-6Al-4V, Ti-6Al-2Mo-2Cr and Ti-6Al-5Mo-5V-1Cr-1Fe (Table 1).

\begin{tabular}{|c|c|c|c|c|c|c|c|c|c|}
\hline \multirow[t]{2}{*}{ Alloy } & \multirow{2}{*}{$\begin{array}{c}\begin{array}{c}\text { Stability } \\
\text { factor of } \boldsymbol{\beta} \text { - } \\
\text { phase }\end{array} \\
\mathrm{K}_{\beta}\end{array}$} & \multicolumn{8}{|c|}{ Alloying elements content, wt. \% } \\
\hline & & $\mathrm{Al}$ & Mo & V & $\mathrm{Cr}$ & Fe & C & Si & $\mathrm{Ti}$ \\
\hline Ti-6Al-4V & 0.3 & 6.1 & - & 4.3 & - & 0.16 & 0.01 & - & bal. \\
\hline Ti-6Al-2Mo-2Cr & 0.6 & 6.3 & 2.6 & - & 2.1 & 0.40 & 0.05 & 0.2 & bal. \\
\hline Ti-6Al-5Mo-5V-1Cr-1Fe & 1.2 & 5.8 & 5.3 & 5.1 & 0.9 & 0.8 & 0.05 & 0.15 & bal. \\
\hline
\end{tabular}

Table 1. Chemical composition of the investigated titanium alloys.

Ti-6Al- $4 \mathrm{~V}-$ martensitic $\alpha+\beta$ alloy $\left(\mathrm{K}_{\beta}=0.3\right)$ - is the most widespread titanium alloy $(>60 \%$ of all titanium alloys produced in USA and EU). Its high applicability results from good balance of mechanical properties and good castability, plastic workability, heat treatability and weldability. Aluminium addition stabilizes and strengthen $\alpha$ phase, increases $\alpha+\beta \leftrightarrow \beta$ transformation temperature and reduces alloy density. Vanadium $-\beta$-stabilizer - reduces $\alpha+\beta \leftrightarrow \beta$ transformation temperature and facilitates hot working (higher volume fraction of $\beta$-phase). Depending on required mechanical properties following heat treatment can be applied to Ti-6Al-4V alloy: partial annealing $\left(600 \div 650^{\circ} \mathrm{C} / 1 \mathrm{~h}\right)$, full annealing $\left(700 \div 850^{\circ} \mathrm{C} /\right.$ furnace cooling to $600^{\circ} \mathrm{C} /$ air cooling) or solutioning $\left(880 \div 950^{\circ} \mathrm{C} /\right.$ water quenching) and ageing $\left(400 \div 600^{\circ} \mathrm{C}\right)[1,3]$.

Ti-6Al-2Mo-2Cr - martensitic $\alpha+\beta$ alloy - known as VT3-1, is one of the first widespread hightemperature titanium alloys used in Russia for aircraft engine elements. Amount of $\beta$ stabilizers is similar to Ti-6Al-4V alloy but $\beta$-stabilizing factor is higher $\left(\mathrm{K}_{\beta}=0.6\right)$. Mo stabilises and strengthens $\beta$-phase, in the presence of $\mathrm{Si}$ increases creep resistance, facilitates plastic working, $\mathrm{Cr}, \mathrm{Fe}-$ eutectoid elements, stabilise $\beta$-phase and strengthen $\alpha$ and $\beta$ phases in the low and medium temperature range [1].

The alloy is processed by forging, stamping, rolling and pressing. Depending on the application and required properties following heat treatment can be applied to the semiproducts: isothermal annealing $\left(870^{\circ} \mathrm{C} / \mathrm{h} /\right.$ furnace cooling to $650^{\circ} \mathrm{C} /$ holding for $2 \mathrm{~h} /$ air cooling), 
duplex annealing $\left(880^{\circ} \mathrm{C} / 1 \mathrm{~h} /\right.$ air cooling and following heating $550^{\circ} \mathrm{C} / 2 \div 5 \mathrm{~h} /$ air cooling) or hardening heat treatment (water quenching and ageing) [1,7].

Ti-6Al-2Mo-2Cr alloy retains its mechanical properties up to $300^{\circ} \mathrm{C}$. At the temperature higher than $400^{\circ} \mathrm{C}$ mechanical properties are reduced due to partitioning of alloying elements proceeding by diffusion.

Ti-6Al-5Mo-5V-1Cr-1Fe transition $\alpha+\beta$ titanium alloy $\left(\mathrm{K}_{\beta}=1.2\right)$ is produced in Russia and Ukraine, where is known as VT22. It is characterized by very good mechanical properties thus is mainly used for large, heavy loaded, forged parts for long-term operation at elevated temperature up to $350 \div 400^{\circ} \mathrm{C}$ and short-term up to $750 \div 800^{\circ} \mathrm{C}$. Typical applications include disks and blades of low pressure compressors, landing gear elements, engine mount struts and others [1,11].

\section{Development of microstructure during continuous cooling}

Phase composition of titanium alloys after cooling from $\beta$ phase range is controlled by cooling rate. Kinetics of phase transformations is related to the value of $\beta$-phase stability coefficient $\mathrm{K}_{\beta}$ resulting from the chemical composition of the alloy [7].

One important characteristic of the alloy is a range of $\alpha+\beta \rightarrow \beta$ phase transformation temperature that determines conditions of thermomechanical processing intended for development of suitable microstructure. Start and finish temperatures of $\alpha+\beta \rightarrow \beta$ phase transformation, vary depending on the contents of $\beta$ stabilizing elements (Table 2).

\begin{tabular}{cccc}
\hline Phase transformation & \multicolumn{1}{c}{ Alloy } & \\
\hline temperature, ${ }^{\circ} \mathbf{C}$ & Ti-6Al-4V & Ti-6Al-2Mo-2Cr & Ti-6Al-5Mo-5V-1Cr-1Fe \\
\hline$T_{a+\beta \rightarrow \beta}^{n s}$ & 890 & 840 & 790 \\
\hline$T_{a+\beta \rightarrow \beta}^{p s}$ & 930 & 920 & 830 \\
\hline$T_{a+\beta \rightarrow \beta}^{f}$ & 985 & 980 & 880 \\
\hline$T_{\beta \rightarrow a+\beta}^{s}$ & 950 & 940 & 810 \\
\hline$T_{\beta \rightarrow a+\beta}^{f}$ & 870 & 850 & \\
\hline ns-nucleation start & & & \\
ps- precipitation start & & & \\
s-start & & & \\
$f-$ finish & & & \\
\hline
\end{tabular}

Table 2. Start and finish temperature of the $\alpha+\beta \rightarrow \beta$ phase transformation for selected titanium alloys $\left(v_{h}=v_{c}=0.08^{\circ} \mathrm{Cs}^{-1}\right)$ 


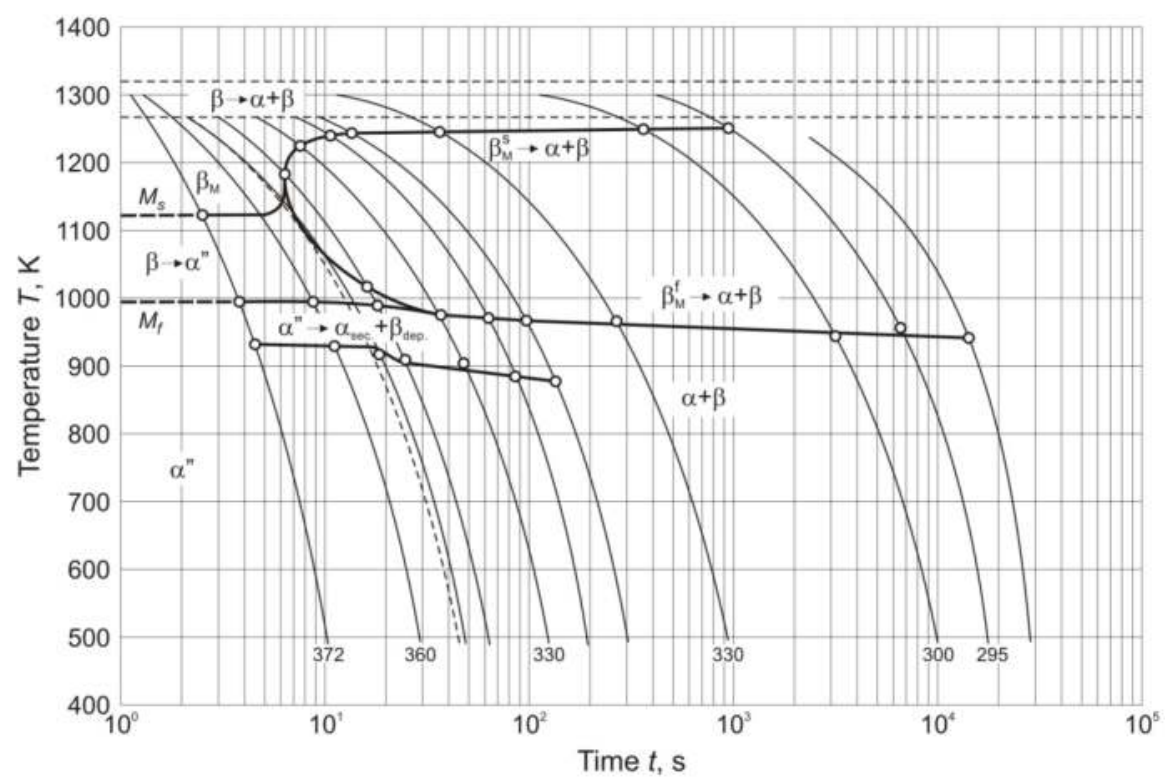

Figure 1. CCT diagram for Ti-6Al-4V alloy.

Cooling of Ti-6Al-2Mo-2Cr and Ti-6Al-4V alloys from above $\beta$ transus temperature at the rate higher than $18^{\circ} \mathrm{C} \mathrm{s}^{-1}$ leads to development of martensitic microstructure consisting of $\alpha^{\prime}\left(\alpha^{\prime \prime}\right)$ phases (Fig. 4). Start and finish temperatures of the martensitic transformation $\beta \rightarrow \alpha^{\prime}\left(\alpha^{\prime \prime}\right)$ or $\beta \rightarrow \alpha^{\prime \prime}$ do not depend on cooling rate but on $\beta$-stabilizing elements content and decrease with increasing $\mathrm{K}_{\beta}$ value.

For the intermediate cooling rates, down to $3.5^{\circ} \mathrm{C} \mathrm{s}^{-1}$, martensitic transformation is accompanied by diffusional transformation $\beta \rightarrow \alpha+\beta$ and the volume fraction of martensitic phases decreases to the benefit of stable $\alpha$ and $\beta$ phases (Figs 1-2). Cooling rates below $2{ }^{\circ} \mathrm{C} \mathrm{s}^{-1}$ lead to a diffusion controlled nucleation and growth of stable $\alpha$ and $\beta$ phases in the shape of colonies of parallel $\alpha$-phase lamellae in primary $\beta$-phase grains (Fig. 5). For extremely low cooling rates precipitations of $\mathrm{TiCr}_{2}$ phase were identified in the Ti-6Al-2Mo-2Cr alloy which were formed in eutectoid transformation.

In the transition alloy $\mathrm{Ti}-6 \mathrm{Al}-5 \mathrm{Mo}-5 \mathrm{~V}-1 \mathrm{Cr}-1 \mathrm{Fe}$ martensitic transformation was not observed at any cooling rate. High cooling rate $\left(>18^{\circ} \mathrm{C} \mathrm{s}^{-1}\right)$ results in metastable $\beta_{\mathrm{M}}$ microstructure. At lower cooling rates $\alpha$-phase precipitates as a result of diffusional transformation. At lowest cooling rate, similarly to Ti-6Al-2Mo-2Cr alloy eutectoid transformation occurs and traces of $\mathrm{TiCr}_{2}$ and $\mathrm{TiFe}_{2}$ appears [7]. 


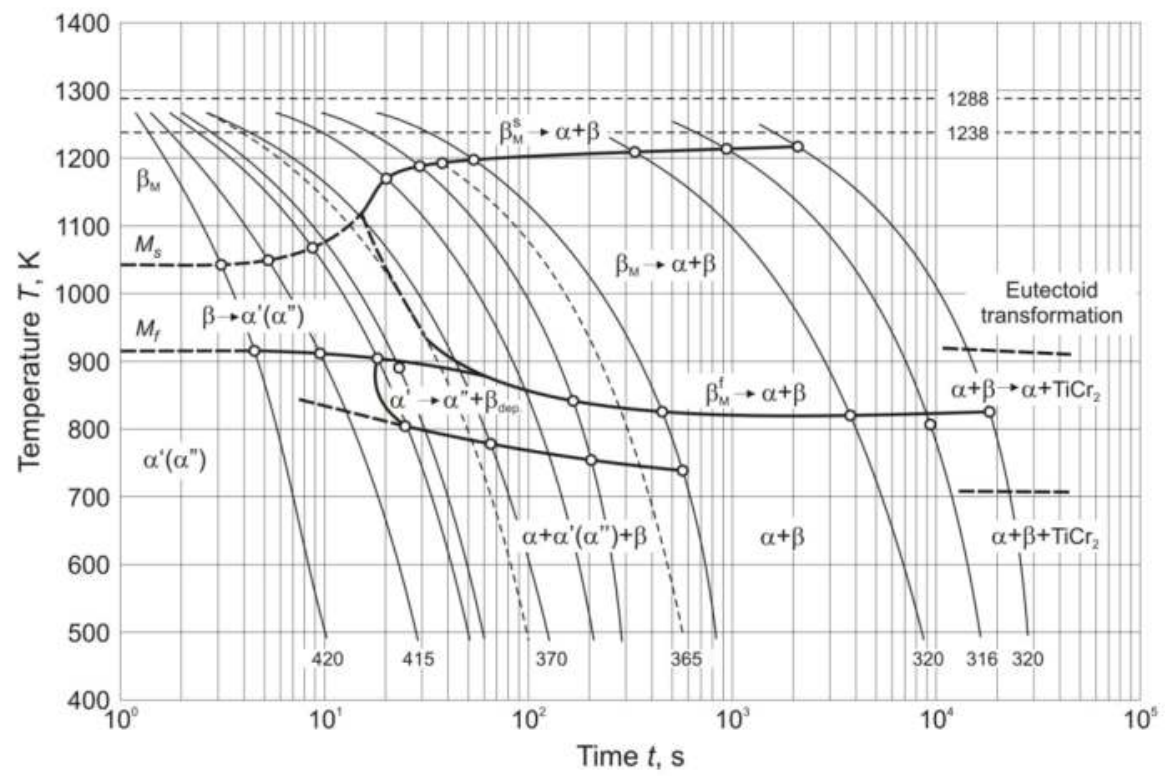

Figure 2. CCT diagram for Ti-6Al-2Mo-2Cr alloy.

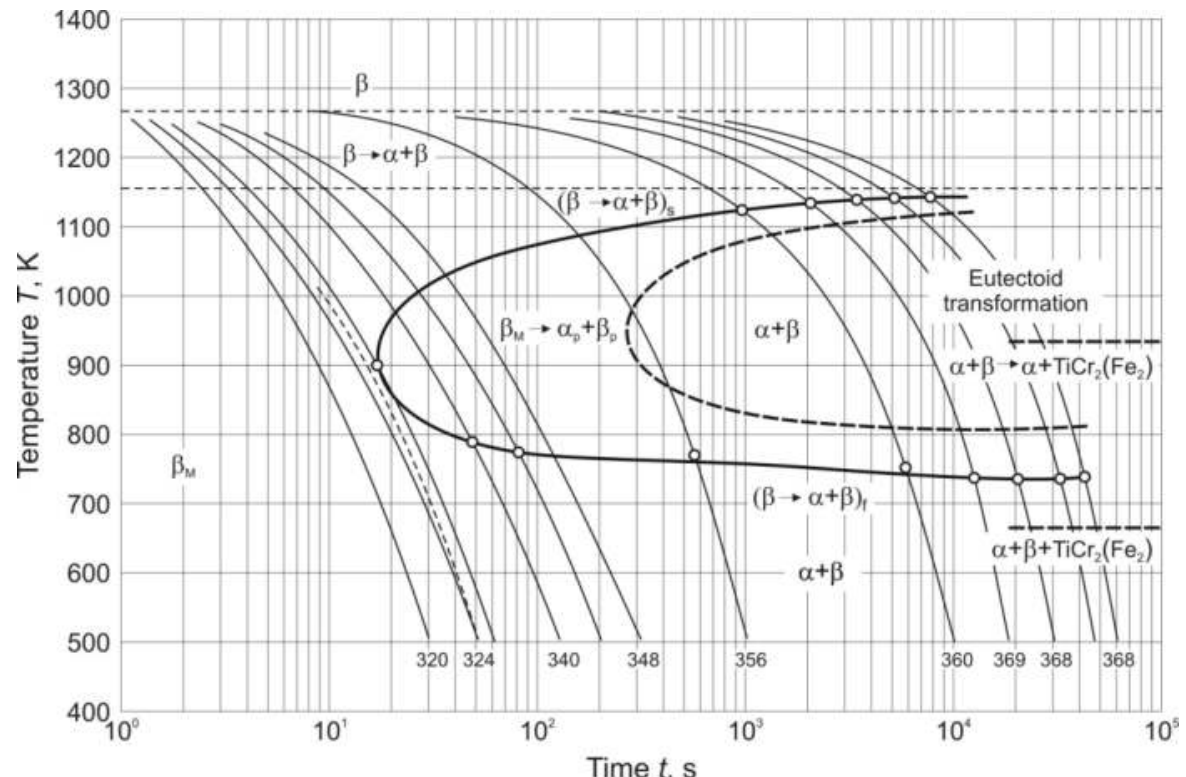

Figure 3. Fig. 3.CCT diagram for Ti-6Al-5Mo-5V-1Cr-1 Fe alloy. 


\begin{tabular}{cccc}
\hline Cooling rate, ${ }^{\circ} \mathrm{C} \cdot \mathbf{s}^{-1}$ & \multicolumn{3}{c}{ Phase composition of the alloy } \\
\hline & Ti-6Al-4V & Ti-6Al-2Mo-2Cr & Ti-6Al-5Mo-5V-1Cr-1Fe \\
\hline $48-18$ & $a^{\prime}\left(a^{\prime \prime}\right)$ & $a^{\prime}\left(a^{\prime \prime}\right)$ & $\beta_{M}$ \\
9 & $a+a^{\prime}\left(a^{\prime \prime}\right)$ & $a+a^{\prime}\left(a^{\prime \prime}\right)+\beta$ & $\beta_{M}+a$ \\
7 & $a+a^{\prime}\left(a^{\prime \prime}\right)$ & $a+a^{\prime}\left(a^{\prime \prime}\right)_{\text {trace }}+\beta$ & $\beta_{M}+a$ \\
3.5 & $a+a^{\prime}\left(a^{\prime \prime}\right)_{\text {trace }}+\beta$ & $a+a^{\prime}\left(a^{\prime \prime}\right)_{\text {trace }}+\beta$ & $\beta_{M}+a$ \\
$1.2-0.04$ & $a+\beta$ & $a+\beta$ & $a+\beta$ \\
$0.024-0.004$ & $a+\beta$ & $a+\beta+\operatorname{TiCr}_{2}$ & $a+\beta+\operatorname{TiCr}_{2}\left(\mathrm{Fe}_{2}\right)$ \\
\hline
\end{tabular}

Table 3. Phase composition of the selected titanium alloys after controlled cooling from the $\beta$-phase range $[6,9]$

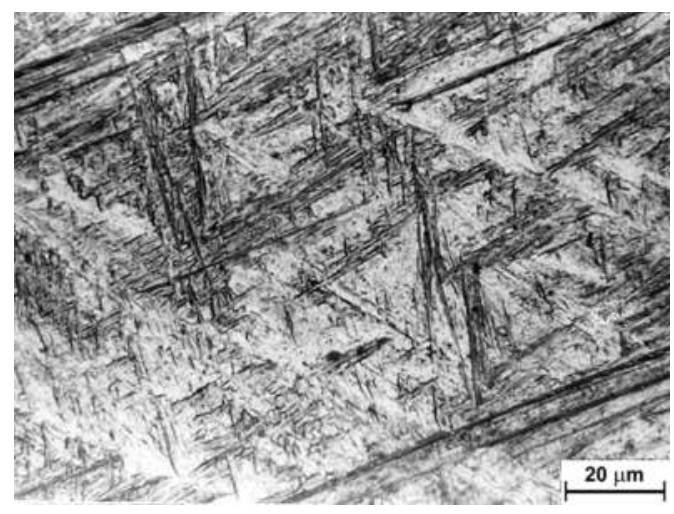

Figure 4. Martensitic microstructure of Ti-6Al-2Mo-2Cr alloy after cooling from $1050^{\circ} \mathrm{C}$ at a rate of $48^{\circ} \mathrm{C} \mathrm{s}^{-1}$ (LM-DIC micrograph).

The important parameters for a lamellar microstructure with respect to mechanical properties of the alloy are the $\beta$-grain size, size of the colonies of $\alpha$-phase lamellae, thickness of the $\alpha$ lamellae and the morphology of the interlamellar interface ( $\beta$-phase) (Fig. 6) [12-13].

Increase in cooling rate leads to refinement of the microstructure - both $\alpha$ colony size and $\alpha$ lamellae thickness are reduced. Additionally new colonies tend to nucleate not only on $\beta$-phase boundaries but also on boundaries of other colonies, growing perpendicularly to the existing lamellae. This leads to formation of characteristic microstructure called "basket weave" or Widmanstätten microstructure (Fig. 7) [3].

\section{Tensile and fatigue properties}

Mechanical properties of two phase titanium alloys strongly depend on morphology of particular phases. In the case of the alloys with lamellar microstructure, the thickness of $\alpha$ lamellae and diameter of their colonies have the most significant influence $[3,14]$. 


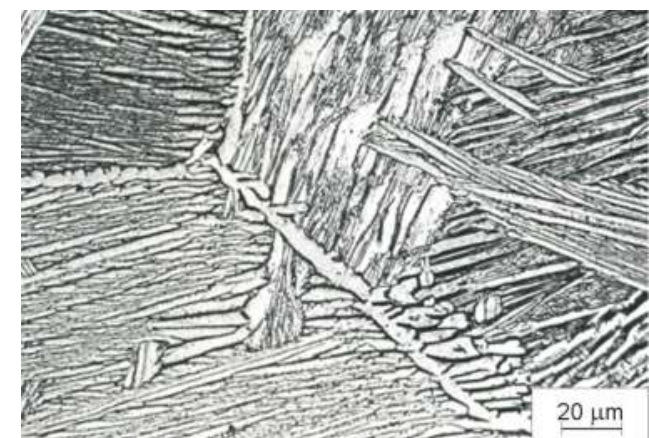

(a)

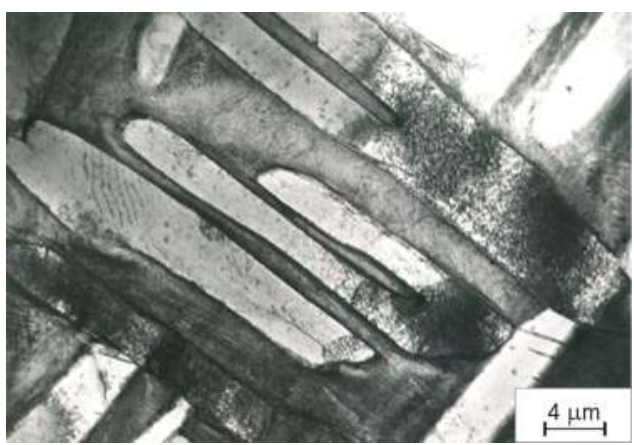

(b)

Figure 5. Microstructure of Ti-6Al-2Mo-2Cr alloys after cooling from $1050^{\circ} \mathrm{C}$ at a rate of $1.2^{\circ} \mathrm{C} \mathrm{s}^{-1}:$ a) $\mathrm{LM} \mathrm{micrograph,} \mathrm{b)}$ TEM micrograph.

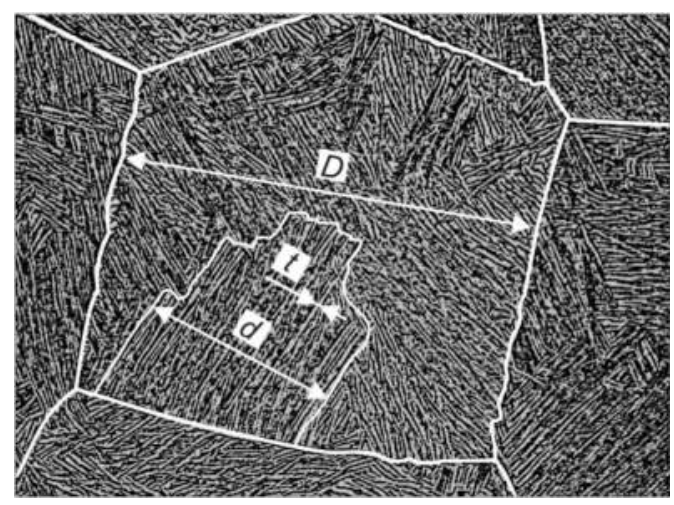

Figure 6. Stereological parameters of lamellar microstructure: $D$ - primary $\beta$-phase grain size, $d$-size of the colony of parallel a-lamellae, $t$ - thickness of a-lamellae.

Refinement of the microstructure results in higher yield stress (Fig. 8a). However the increase of yield stress is moderate unless martensitic phase is present. Tensile elongation increases with increasing cooling rate at first (Fig. 8b). However, after reaching maximum the ductility curve declines. Such behaviour was reported earlier and attributed to the change of fracture mode from ductile transcrystalline for low cooling rates to ductile intercrystalline fracture along continuous $\alpha$ phase layers at primary $\beta$ grain boundaries $[6,8]$.

The size of the colonies of $\alpha$ lamellae having the same crystallographic orientation have significant influence on the mechanical properties of the alloy as it is a measure of effective slip length $[8,15]$. However transition to the 'basket weave' type of microstructure makes the determination of colonies size even more difficult. Because of that the thickness of $\alpha$-lamellae was also taken into account as the quantitative parameter illustrating the effect of microstructure refinement on mechanical properties. 


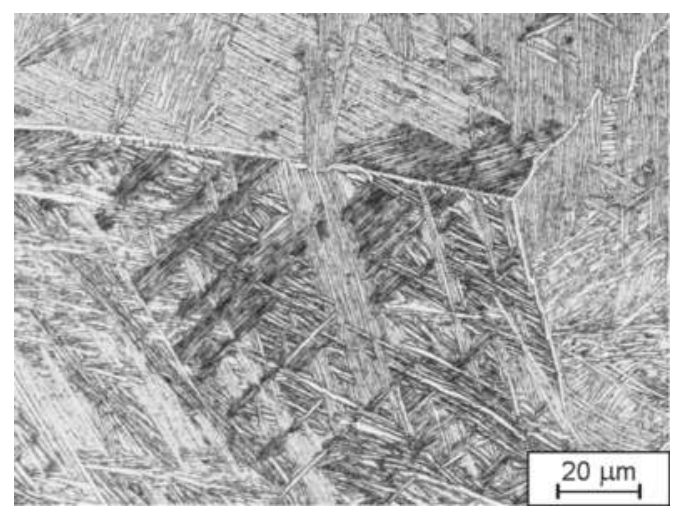

Figure 7. "Basket-weave" or Widmanstätten microstructure of Ti-6Al-4V alloy after cooling from $\beta$-phase range at the rate of $9^{\circ} \mathrm{Cs}^{-1}$.

a)

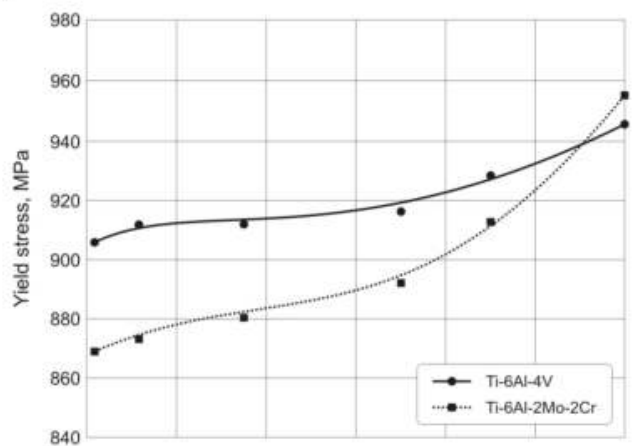

b)

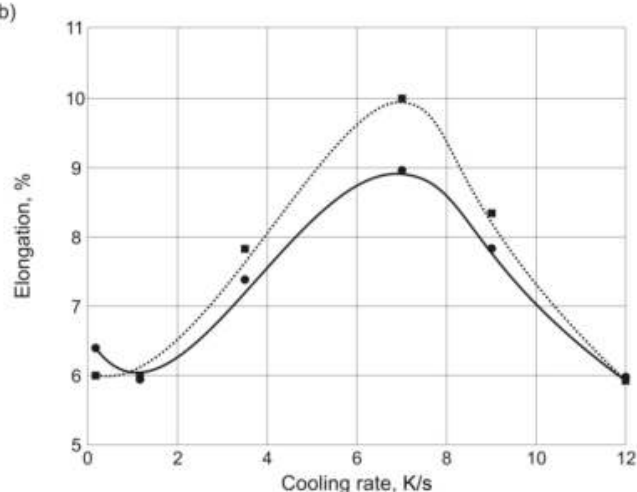

Figure 8. Yield stress and tensile elongation dependence on the cooling rate from $\beta$-phase range for selected titanium alloys. 


\begin{tabular}{ccccc}
\hline $\begin{array}{c}\text { Average thickness of } \\
\mathbf{a}-\text {-phase lamellae, } \boldsymbol{\mu m}\end{array}$ & $\begin{array}{c}\text { YS, } \\
\text { MPa }\end{array}$ & $\begin{array}{c}\text { UTS, } \\
\mathbf{M P a}\end{array}$ & $\begin{array}{c}\boldsymbol{\sigma}_{\mathbf{f}} \\
\mathbf{M P a}\end{array}$ & HV \\
\hline 2.4 & 970 & 1115 & 565 & 326 \\
\hline 3.0 & 928 & 1068 & 580 & 330 \\
\hline 5.5 & 916 & 1056 & 570 & 336 \\
\hline 7.6 & 908 & 1038 & 560 & \\
\hline$\sigma_{f}-$ fatigue strength at $10^{7}$ cycles in rotational bending test. & & & \\
\hline
\end{tabular}

Table 4. Mechanical properties of the Ti-6Al-4V alloy

\begin{tabular}{ccccc}
\hline $\begin{array}{c}\text { Average thickness of } \boldsymbol{a} \text {-phase } \\
\text { lamellae, } \boldsymbol{\mu m}\end{array}$ & $\begin{array}{c}\text { YS, } \\
\text { MPa }\end{array}$ & $\begin{array}{c}\text { UTS, } \\
\text { MPa }\end{array}$ & $\begin{array}{c}\boldsymbol{\sigma}_{\mathbf{f}} \\
\mathbf{M P a}\end{array}$ & HV \\
\hline 1.7 & 980 & 1136 & 550 & 340 \\
\hline 2.0 & 944 & 1108 & 575 & 338 \\
\hline 3.6 & 924 & 1055 & 560 & 332 \\
\hline 6.2 & 922 & 1024 & 540 & 336 \\
\hline
\end{tabular}

Table 5. Mechanical properties of the Ti-6Al-2Mo-2Cr alloy.

\begin{tabular}{ccccc}
\hline $\begin{array}{c}\text { Average thickness of } \boldsymbol{\alpha} \text {-phase } \\
\text { lamellae, } \boldsymbol{\mu m}\end{array}$ & $\begin{array}{c}\text { YS, } \\
\text { MPa }\end{array}$ & $\begin{array}{c}\text { UTS, } \\
\text { MPa }\end{array}$ & $\begin{array}{c}\boldsymbol{\sigma}_{\mathbf{f}}, \\
\mathbf{M P a}\end{array}$ & HV \\
\hline 0.8 & 1235 & 1305 & 540 & 348 \\
\hline 1.5 & 1225 & 1285 & 555 & 340 \\
\hline 2.6 & 1186 & 1262 & 535 & 342 \\
\hline 4.3 & 1160 & 1236 & 520 & 336 \\
\hline
\end{tabular}

Table 6. Mechanical properties of the Ti-6Al-5Mo-5V-1Cr-1Fe alloy.

Following values of geometrical parameters of lamellar $\alpha$-phase, i.e. thickness of the $\alpha$-lamellae $(t)$ and diameter of the $\alpha$-phase lamellae colony $(d)$, provided maximum fatigue strength of the investigated alloys:

- Ti-6Al-2Mo-2Cr $t=2 \mu \mathrm{m}, d=20 \mu \mathrm{m}$,

- Ti-6Al-4V $t=3 \mu \mathrm{m}, d=30 \mu \mathrm{m}$,

- Ti-6Al-5Mo-5V-1Cr-1Fe $t=1.5 \mu \mathrm{m}, d=35 \mu \mathrm{m}$.

Fatigue fracture surfaces showed transgranular character with typical ductile surroundings of $\beta$-phase around $\alpha$-phase (Fig. 9). Size of the dimples were closely related to thickness of the $\alpha$-lamellae and size of the colonies of parallel $\alpha$-lamellae [16]. No pronounced beach markings 
or striations were identified which is an evidence of frequent change of the crack growth direction. This phenomenon along with secondary crack branching are important reasons for advantageous effect of lamellar microstructure on fatigue behaviour.

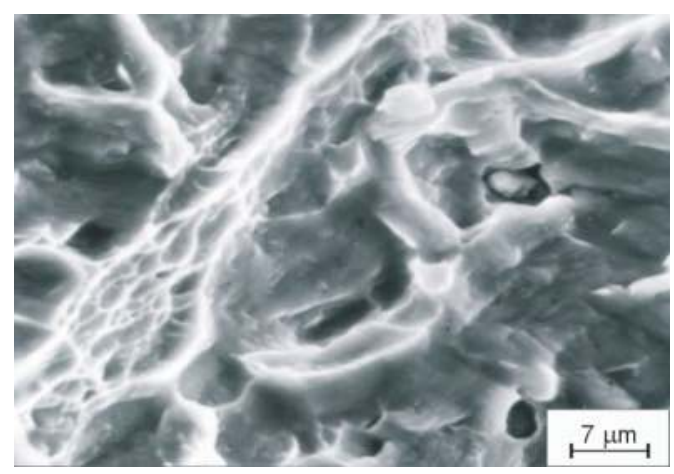

Figure 9. Fatigue fracture surfaces of Ti-6Al-5Mo-5V-1Cr-1 Fe alloy cooled from $1020^{\circ} \mathrm{C}$ at a rate of $0.8^{\circ} \mathrm{C} \mathrm{s}^{-1}$.

The progress of the crack tip through regions of interfacial $\beta$-phase is accompanied by the absorption of large amount of energy due to intensive plastic deformation, contributing to lowering the rate of crack propagation. When thickness of $\beta$-phase regions decreases, it cannot absorb sufficient amounts of energy and retard the crack propagation.

\section{Summary}

Microstructure of two-phase titanium alloys after deformation or heat treatment carried out at a temperature in the range of $\beta$-phase stability depends on cooling rate. High cooling rates $\left(>18^{\circ} \mathrm{C} \mathrm{s}^{-1}\right)$ result in martensitic $\alpha^{\prime}\left(\alpha^{\prime \prime}\right)$ microstructure for alloys having $\beta$ stability factor $\mathrm{K}_{\beta}<1$ and metastable $\beta_{\mathrm{M}}$ microstructure for alloys with higher contents of $\beta$-stabilizers. Low and moderate cooling rates lead to development of lamellar microstructure consisting of colonies of $\alpha$-phase lamellae within large $\beta$-phase grains. Decrease of cooling rate cause increase both in thickness of individual $\alpha$-phase lamellae and size of the colonies of parallel $\alpha$-lamellae. This in turn lowers yield stress and tensile strength of the alloys.

Lamellar $\alpha$-phase microstructure of the alloy heat treated in the $\beta$-range has beneficial effect on its fatigue behaviour. This is the result of frequent change in crack direction and secondary crack branching. When $\alpha$-phase lamellae are too large thin layers of $\beta$-phase are not capable to absorb large amounts of energy and retard the crack propagation. In this case the colony of the $\alpha$-phase lamellae behaves as singular element of the microstructure. This phenomenon is more intensive in the alloy with smaller value of $\mathrm{K}_{\beta}$ coefficient (Ti-6Al-4V). Sufficient thickness of $\beta$-phase surroundings enables absorption of energy in the process of plastic deformation of regions ahead of the crack tip, contributing to slowing the rate of crack propagation and therefore increasing fatigue life. 


\section{Author details}

J. Sieniawski, W. Ziaja, K. Kubiak and M. Motyka

Rzeszów University of Technology, Dept. of Materials Science, Poland

\section{References}

[1] Bylica A, Sieniawski J. Titanium and Its Alloys. PWN, Warsaw, Poland, (1985). (in Polish).

[2] Williams J. C, Starke Jr. E. A. Progress in structural materials for aerospace systems. Acta Materialia. (2003). 51(19):5775-5799.

[3] Lutjering G, Williams J C. Titanium. Springer-Verlag, Berlin, 2007.

[4] Lütjering G. Property optimization through microstructural control in titanium and aluminum alloys. Materials Science and Engineering. (1999). A263(1-2):117-126.

[5] Markovskya P. E, Semiatin S. L. Tailoring of microstructure and mechanical properties of Ti-6Al-4V with local rapid (induction) heat treatment. Materials Science and Engineering. (2011). A528(7-8):3079-3089.

[6] Sieniawski J, Filip R, Ziaja W. The effect of microstructure on the mechanical properties of two phase titanium alloys. Materials \& Design. (1997). 18(4-6):361-363.

[7] J. Sieniawski, Phase transformations and microstructure development in multicomponent titanium alloys containing $\mathrm{Al}, \mathrm{Mo}, \mathrm{V}$ and $\mathrm{Cr}$, Oficyna Wydawnicza Politechniki Rzeszowskiej, Rzeszów, (1985). (in Polish).

[8] Lütjering G. Influence of processing on microstructure and mechanical properties of (+) titanium alloys. Materials Science and Engineering. (1998). A243(1-2):32-45.

[9] Kubiak K, Sieniawski J. Development of the microstructure and fatigue strength of two-phase titanium alloys in the processes of forging and heat treatment. Journal of Materials Processing Technology. (1998) 78(1-3):117-121.

[10] Nalla R. K, Boyce B. L, Campbell J. P, Peters J. O, Ritchie R. O. Influence of microstructure on high-cycle fatigue of Ti-6Al-4V: bimodal vs. lamellar structures. Metallurgical and Materials Transactions. (2002). 33A(3):899-918.

[11] Moiseyev VN. Titanium alloys. Russian aircraft and aerospace applications. Taylor \& Francis. New York. (2006).Tiley J, Searles T, Lee E, Kar S, Banerjee R, Russ J. C, Fraser H. L. Quantification of microstructural features in / titanium alloys. Materials Science and Engineering. (2004). A372(1-2):191-198. 
[12] Filip R, Kubiak K, Ziaja W, Sieniawski J. The effect of microstructure on the mechanical properties of two-phase titanium alloys, Journal of Materials Processing Technology. (2003). 133(1-2):84-89.

[13] Sieniawski J, Grosman F, Filip R, Ziaja W. Microstructure factors in fatigue damage process of two-phase titanium alloys. Titanium '95 Science and Technology, P.A. Blenkinsop, W.J. Evans and H.M. Flower eds., The Institute of Materials, Birmingham. (1996). 1411-1418.

[14] Gil F. J, Manero J. M, Ginebra M. P, Planell J. A. The effect of cooling rate on the cyclic deformation of -annealed Ti-6Al-4V. Materials Science and Engineering. (2003). A349(1-2):150-155.

[15] Ziaja W, Sieniawski J, Kubiak K, Motyka M.: Fatigue and microstructure of two phase titanium alloys. Inżynieria Materiałowa. (2001). 22(3):981-985. 